\title{
O ACTUAL COMPORTAMENTO DOS CONSUMIDORES COMO UMA OPORTUNIDADE PARA AS PME'S PORTUGUESAS. UM EXEMPLO NO SECTOR DO VESTUÁRIO «SPORTSWEAR»
}

\author{
Carlos Pedro Baião da Cruz*
}

\section{INTRODUÇÃO}

É um dado adquirido, da economia em geral e dos seus agentes em particular, que os principais aspectos de que carecem as pequenas e médias empresas (PME), nomeadamente as que constituem a grande maioria do tecido industrial português, são os que resultam do desenvolvimento da função de Marketing numa empresa.

Podemos então afirmar, como tem sido referido pelos mais diversos especialistas, que a principal desvantagem competitiva das PME's nacionais é a abordagem do seu negócio numa prespectiva puramente industrial, deixando esquecidas funções tão importantes como as Comerciais e de Marketing.

É no contexto actual de constantes mutações económico-sociais que vamos tentar analisar quais as possibilidades de empresas com as características das nossas e que constituem a grande maioria da indústria portuguesa, face à mudança de comportamentos da sociedade, em geral, e da economia, em particular. Pensamos que, fazer com que as nossas PME's e seus gestores percorram as mesmas etapas de desenvolvimento que as suas congéneres europeias, não é o caminho mais prático e realista a seguir. Devemos antes aproveitar as grandes transformações económicas dos últimos cinco anos, que nos dão algumas vantagens competitivas, face ao baixo nível de gestão empresarial que possuímos.

Um dos aspectos que nos parece bastante importante neste contexto é o comportamento actual dos consumidores, como uma das variáveis mais importantes na análise estratégica das PME's nacionais .

* Director Geral da Branaldo. 


\section{ANÁLISE DA RELAÇÃO OFERTA INDUSTRIAL/PROCURA DO MER- CADO, E A SUA INFLUÊNCIA NA DESREGULAÇÃO DO PREÇO}

O declínio do consumo, ou de um certo tipo de consumo tal como era conhecido, tem vindo a ser acentuado na maioria dos sectores industriais. Podemos dizer hoje que uma certa forma de sociedade de consumo está morta ou em vias de desaparecimento. Encontramo-nos, assim, perante uma sociedade do pós-consumismo, esta muito mais aleatória nos seus comportamentos, marcada por bastantes perigos e muitas incertezas (B. Devez, 1992).

É uma situação de crise social, económica, de emprego e de consumo que nos leva a questionar sobre o comportamento dos consumidores, face à relação "preço/marca", e qual a sua tendência futura.

O problema dos preços, a sua evolução e o comportamento dos consumidores, face ao mesmo, é inseparável de uma dupla evolução sistemática "oferta/procura". É conveniente analisar e descrever este duplo sistema:

\section{"Sistema da Oferta"}

Os industriais, os produtores, os distribuidores, os comunicadores..., de uma forma geral, são os actores da vida social e económica que propõem, concebem, fabricam e distribuem os produtos e serviços.

\section{"Sistema da Procura"}

Os consumidores, o público em geral, suas motivações, suas necessidades, o seu sistema de valores, os seus modos de vida e os seus desejos reais ou imaginários.

Constatamos que estes dois sistemas, na última década, conheceram fortes evoluções, essencialmente devidas às grandes transformações socioeconómicas verificadas à escala mundial. Não exageramos se falarmos numa mudança radical dos sistemas produtivos, tanto a nível nacional, como mundial, e o mesmo se poderá afirmar, de uma forma geral, relativamente às mudanças sócio-culturais dos consumidores e do consumo.

Analisando o comportamento destas duas fileiras (Sistemas da Procura e da Oferta), verificamos que a simultaneidade evolutiva não é fortuita, pois aquelas tendem a ajustar-se continuamente. É curioso verificar que o comportamento destes dois sistemas tendem para um fim comum que tem como consequência a desregulação do sistema de preços, tal como era conhecido no passado.

Assim, vamos analisar alguns aspectos que sofreram grandes evoluções nestes dois sistemas e que contribuem para a desregulação do preço. 


\subsection{Factores relevantes na evolução do sistema oferta}

Os factores que seguramente mais influenciaram o lado da oferta foram os seguintes:

- A mundialização da economia.

- O uso de tecnologia de ponta.

- Explosão na inovação e criação de novos produtos.

- Desenvolvimento de novas formas de distribuição (lojas de desconto, venda por catálogo, ...).

Após analisarmos cada um destes aspectos com mais detalhe, podemos verificar que a desregulação do preço, no lado da oferta, o pressiona no sentido da descida. Senão vejamos alguns mecanismos:

\section{MECANISMOS DE DESREGULAÇÃO DOS PREÇOS}

\begin{tabular}{|c|c|c|}
\hline $\begin{array}{c}\text { Factor de } \\
\text { Transformação }\end{array}$ & Mecanismo & Influência no Preço \\
\hline $\begin{array}{l}\text { Mundialização da eco- } \\
\text { nomia. }\end{array}$ & $\begin{array}{l}\text { Leva a que as estruturas produtivas se } \\
\text { desloquem para os países em vias de } \\
\text { desenvolvimento (PVD). } \\
\text { (ver grafico da engrenagem de desloca- } \\
\text { lização) }\end{array}$ & \multirow{4}{*}{$\begin{array}{l}\text { Oferta a preços mais } \\
\text { baixos }\end{array}$} \\
\hline $\begin{array}{l}\text { Uso de tecnologia de } \\
\text { ponta. }\end{array}$ & $\begin{array}{l}\text { O uso generalizado de teconologia de } \\
\text { ponta e a facilidade na sua aquisição } \\
\text { introduzem em todos os processos } \\
\text { produtivos elevados ganhos de pro- } \\
\text { dutividade. }\end{array}$ & \\
\hline $\begin{array}{l}\text { Explosão na inovação e } \\
\text { criação de novos pro- } \\
\text { dutos. }\end{array}$ & $\begin{array}{l}\text { Conduz a uma diminuição dos ciclos } \\
\text { de vida dos produtos e, consequente- } \\
\text { mente, ao desenvolvimento do fenó- } \\
\text { meno da "hiper-escolha". }\end{array}$ & \\
\hline $\begin{array}{r}\text { Desnvolvimento de novas } \\
\text { formas de distribuição }\end{array}$ & $\begin{array}{l}\text { O aparecimento de novas formas ino- } \\
\text { vadoras de distribuição, tais como as } \\
\text { grandes superfícies, os "hard-dis- } \\
\text { counters", as vendas por catálogo, } \\
\text { etc., vieram introduzir tensões con- } \\
\text { correnciais entre os produtores, por } \\
\text { via do preço. }\end{array}$ & \\
\hline
\end{tabular}


Na vertente do consumo e seus agentes - os consumidores - vamos tentar isolar um certo número de factores que influenciam o seu comportamento, face à oferta "preço". Em primeiro lugar, constatamos na sociedade em geral uma corrente sócio-cultural, de autonomia individual e de expressão pessoal, que tem como consequência mais importante a inexistência de um consumidor médio global e anónimo. É o que hoje podemos caracterizar como "consumidor múltiplo", ou seja, consumidores em busca da sua identidade, de um modo de vida mais original, mais específico. Isto conduz-nos a dizer que não existem generalismos de hierarquia dos factores explicativos de consumo: eles estão todavia presentes na sociedade, mas não nas mesmas pessoas; ou, ainda, eles podem estar presentes nas mesmas pessoas, mas não no mesmo momento, não nas mesmas circunstâncias, ou não relativamente ao mesmo produto ou tipo de produto ou de consumo.

\section{ENGRENAGEM DA DESLOCALIZAÇÃO}

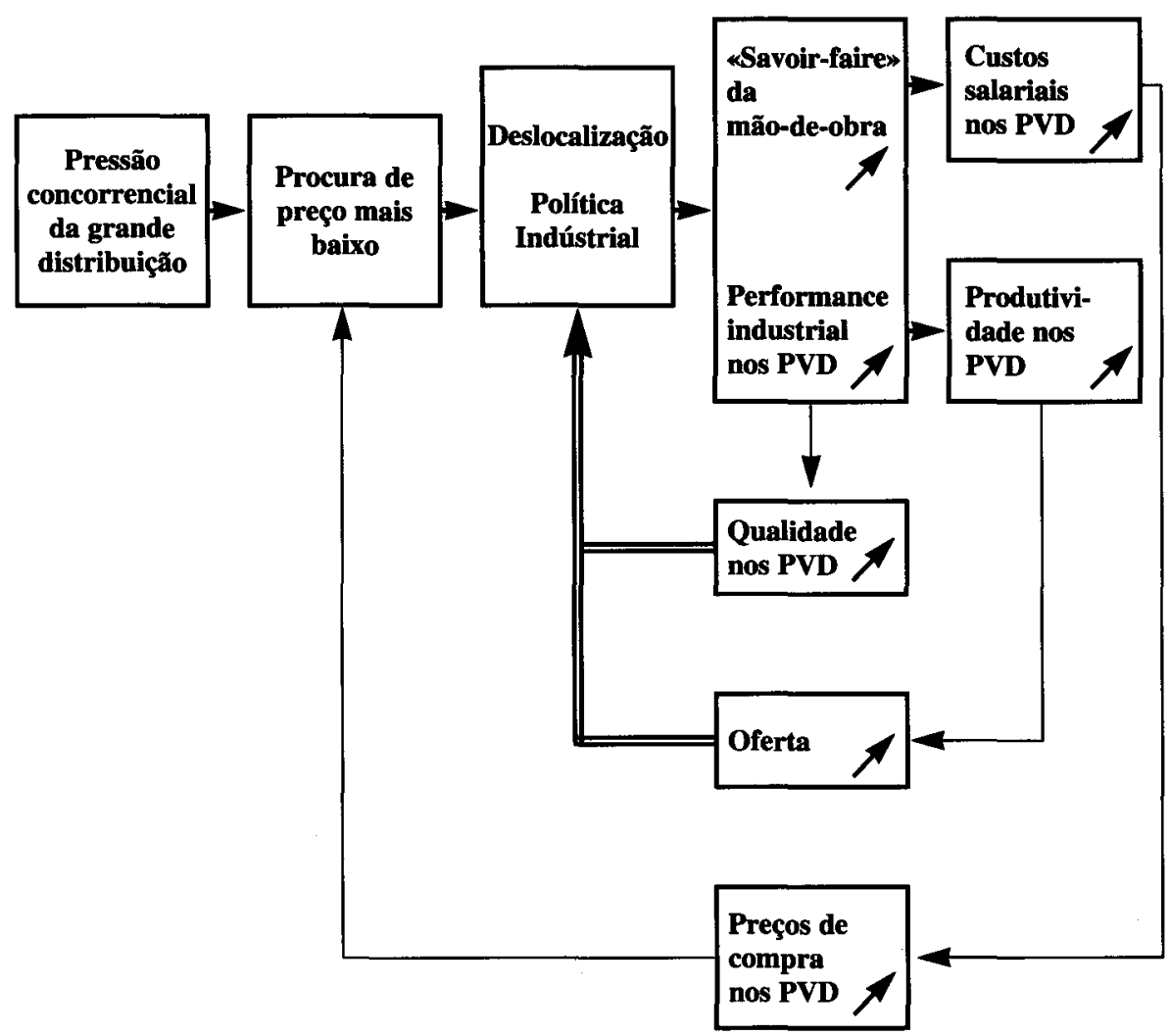




\subsection{Factores relevantes na evolução do sistema oferta}

(reacção do Sistema Procura face à desregulação do preço)

- Clima social, político e económico de ansiedade e desilusão generalizado.

- Declínio relativo da valorização da função compra.

- Sensação crescente de saturação da noção novidade.

- Profusão da "hiper-escolha".

- Dúvidas do consumidor sobre o significado real de "preço" justo.

- Aumento da "Procura Activa".

- Erosão da publicidade e das tradicionais formas de comunicação massivas.

Vejamos quais os mecanismos destes factores e o seu reflexo no consumo:

MECANISMO DE EVOLUÇÃO DO CONSUMO

\begin{tabular}{|c|c|c|}
\hline $\begin{array}{c}\text { Factor de } \\
\text { Transformação }\end{array}$ & Mecanismo & Influência no consumo \\
\hline $\begin{array}{c}\text { Clima social, político e } \\
\text { económico de ansie- } \\
\text { dade e desilusão gene- } \\
\text { ralizado. }\end{array}$ & $\begin{array}{r}\text { A desilusão, relativamente ao passado } \\
\text { da guerra fria e aos sistemas sócio- } \\
\text {-políticos do Leste, bem como o clima } \\
\text { de incerteza trazido pelos focos de } \\
\text { conflito em vários pontos do globo, } \\
\text { fazem com que as perspectivas futu- } \\
\text { ras relativamente ao emprego e às } \\
\text { condições de vida das crianças e das } \\
\text { famílias sejam bastante negativas. }\end{array}$ \\
\hline $\begin{array}{c}\text { Declínio relativo da } \\
\text { valorização da função } \\
\text { compra. }\end{array}$ & $\begin{array}{c}\text { Numa sociedade, onde as clivagens } \\
\text { sociais tendem a esvanecer-se (pelo } \\
\text { menos nos estratos sociais de maior } \\
\text { impacto no consumo), o consumo } \\
\text { motivado pela ostentação social } \\
\text { tende a diminuir, e podemos dizer } \\
\text { que hoje o luxo tende a possuir-se de } \\
\text { uma forma mais discreta. Este feno- } \\
\text { meno traz-nos uma maior consciên- } \\
\text { cia colectiva sobre a noção complexa } \\
\text { de utilidade real: que necessidade } \\
\text { satisfaço com a sua utilização? }\end{array}$ \\
Crescente saturação da \\
noção "novidade". & $\begin{array}{c}\text { No vestuário esta tendência é muito } \\
\text { importante, uma vez que cada vez } \\
\text { menos pessoas reagem à novidade } \\
\text { (colecções) e guardam as suas peças } \\
\text { de uma estação para a outra. }\end{array}$ \\
consumo \\
Dimuição do
\end{tabular}




\begin{tabular}{|c|c|c|}
\hline $\begin{array}{l}\text { Profusão da "hiper- } \\
\text {-escolha". }\end{array}$ & $\begin{array}{l}\text { Existem hoje no mercado inúmeras } \\
\text { possibilidades de escolha de um } \\
\text { mesmo produto, o que torna cada vez } \\
\text { mais difícil a compra, uma vez que os } \\
\text { consumidores estão cada vez mais } \\
\text { sensíveis à relação "preço/quali- } \\
\text { dade". }\end{array}$ & \multirow{4}{*}{$\begin{array}{l}\text { Diminuição do } \\
\text { consumo }\end{array}$} \\
\hline $\begin{array}{l}\text { Dúvidas do consumidor } \\
\text { sobre o significado real } \\
\text { de preço, preço justo } \\
\text { ou de preço normal. }\end{array}$ & $\begin{array}{l}\text { A quantidade de mecanismos de desre- } \\
\text { gulação do preço no Sistema Oferta } \\
\text { constitui um factor básico de dúvida } \\
\text { sobre o verdadeiro valor dos produtos } \\
\text { e da realidade de que são feitos. }\end{array}$ & \\
\hline $\begin{array}{l}\text { Procura activa por parte } \\
\text { dos consumidores. }\end{array}$ & $\begin{array}{l}\text { E hoje uma atitude corrente e quotidi- } \\
\text { ana dos consumidores buscarem sem- } \\
\text { pre, e em qualquer lugar, o melhor } \\
\text { produto ao menor preço. A resposta a } \\
\text { esta atitude pelo lado da oferta foi o } \\
\text { aparecimento imediato de novas for- } \\
\text { mas de distribuição como, entre } \\
\text { outras, as lojas de desconto. }\end{array}$ & \\
\hline $\begin{array}{l}\text { Erosão da publicidade } \\
\text { massificada. }\end{array}$ & $\begin{array}{l}\text { A publicidade massificada é hoje con- } \\
\text { siderada, pela maior parte dos consu- } \\
\text { midores, como uma forma clássica de } \\
\text { sedução comercial. }\end{array}$ & \\
\hline
\end{tabular}

Estamos hoje, provavelmente, do ponto de vista social, psicológico e económico, em termos mundiais, a entrar numa sequência histórica que deverá representar uma espiral de diminuição do consumo e uma espiral deflacionista.

\section{ANÁLISE DO SECTOR TÊXTIL E CONFECÇÕES EM PORTUGAL}

Nesta análise iremos estudar o sector Têxtil e do Vestuário no seu conjunto e, em seguida, abordaremos o sector das Confecções como um subsector (Vasconcelos e Sá: 90).

O peso do sector Têxtil e Confecções (TC) na economia nacional pode ser ilustrado pelo QUADRO I que a seguir se apresenta. 


\section{QUADRO I}

A «PERFORMANCE» DA INDÚSTRIA TÊXTIL E CONFECÇÕES NOS ANOS 80 (valores médios para a década)

\begin{tabular}{|c|c|c|c|c|c|}
\hline & $\begin{array}{c}\text { Produção } \\
\text { (1) }\end{array}$ & $\begin{array}{c}\text { Valor } \\
\text { Acrescentado } \\
\text { (1) }\end{array}$ & $\begin{array}{c}\text { Invest. em } \\
\text { Equipamento } \\
\text { (1) }\end{array}$ & Emprego & $\begin{array}{c}\text { Exportação } \\
\text { (1) }\end{array}$ \\
\hline $\begin{array}{l}\text { A-Têxtil } \\
\text { e Vestuário }\end{array}$ & 355181 & 129243 & 16277 & 185278 & 297703 \\
\hline $\begin{array}{l}\text { B-Indústria } \\
\text { em geral }\end{array}$ & 2238853 & 655750 & 90914 & 658336 & 1114558 \\
\hline C- $\mathbf{A} / \mathbf{B}$ & $16 \%$ & $20 \%$ & $18 \%$ & $28 \%$ & $27 \%$ \\
\hline $\begin{array}{l}\text { D-Valor médio } \\
\text { de crescimento } \\
\text { de } \mathrm{A} \\
\text { nos anos } 80\end{array}$ & $19,6 \%$ & $19,9 \%$ & $23,1 \%$ & $0,19 \%$ & $30,1 \%$ \\
\hline
\end{tabular}

Fonte: INE

(1) Biliōes de escudos, a preços correntes

Comparando o sector TC com o resto da indústria, em geral, verificamos que este possui as seguintes particularidades:

1 - Este sector é mais orientado para a exportação (as exportações representam $83.7 \%$ da produção no sector, comparadas com $49.8 \%$ do resto da indústria, o que equivale a uma diferença de $68 \%$ [83.7/ 49.8=1.68]).

2 - Maior componente de mão-de-obra (a rácio Produção/Emprego na indústria em geral e no sector TC é de 1.9 e 3.4, respectivamente).

3 - Criou mais valor acrescentado (a rácio Valor Acrescentado/Produção é de $36.4 \%$ para o sector e $29.8 \%$ para o resto da indústria).

4 - $O$ investimento em equipamento em proporção ao total da Produção foi semelhante ao do resto da indústria, $4.6 \%$ e $4 \%$ respectivamente.

O QUADRO II mostra a forma como evoluiu o sector durante a última década, comparativamente ao resto da indústria. 
QUADRO II

COMPARAÇÃO ENTRE O SECTOR TC E O RESTANTE SECTOR PRODUTIVO

\begin{tabular}{|l|c|c|}
\hline \multicolumn{1}{|c|}{ Têxtil e Confecções } & $\begin{array}{c}\text { Rácio de 1980-Rácio de 1988 } \\
(1)\end{array}$ & $\begin{array}{l}\text { Rácio do crescimento médio do } \\
\text { sector TC relativamente ao total } \\
\text { da indústria (entre 1980 e 1988) }\end{array}$ \\
\hline Indicadores & $+6.68 \%$ & $-0.45 \%$ \\
Produção & $+7.52 \%$ & $-0.36 \%$ \\
Valor Acrescentado & $-22.83 \%$ & $+2.52 \%$ \\
Investimento em Equipamento & $-32.78 \%$ & $+1.66 \%$ \\
Exportação & $-35.80 \%$ & $+1.56 \%$ \\
Emprego & & \\
\hline
\end{tabular}

Fonte: INE

(1) $\frac{\text { Indicador do sector em } 198 \ldots}{\text { Indicador para toda a indústria em } 198 \ldots} * 100$

Da análise deste quadro podemos verificar que tanto a Produção como o Valor Acrescentado do sector diminuíram o seu peso, relativamente ao total da indústria, enquanto que o Investimento em Equipamento e em Exportações aumentou o respectivo peso.

Similarmente as rácios de crescimento da Produção e Valor Acrescentado do sector foram inferiores às rácios de crescimento do total da indústria, o que confirma a afirmação do parágrafo anterior. No entanto, as rácios de crescimento das Exportações e dos Investimentos foram superiores às verificadas no resto da indústria.

O crescimento médio do Produto Nacional na década de oitenta foi de $21.73 \%$, superior $2.11 \%$ à rácio de crescimento da Produção nos Têxteis e Confecções (19.63\%, preços correntes).

A conclusão geral que podemos tirar é que, durante a última década, o sector perdeu peso no global da economia portuguesa. No entanto, tentou compensar este facto investindo muito na reconversão do seu equipamento e tornando-se mais exportador. De qualquer forma, o sector não conseguiu evitar crescer menos que o resto da economia nacional.

\subsection{A «perfomance» no subsector das confecções.}

O QUADRO III mostra a análise feita por subsectores. Nos quadros 3.1 e 3.2 160 estão os valores apresentados do QUADRO II, mas agora somente para os sub- 
sectores Têxtil e Confecções, respectivamente. O quadro 3.3 compara os valores, entre os subsectores Têxtil e Confecções, dos diversos indicadores.

\section{QUADRO III}

COMPARAÇÃO ENTRE OS SUBSECTORES TÊXTIL E CONFECÇÕES NA DÉCADA DE 80

\begin{tabular}{|l|c|c|c|c|}
\hline \multicolumn{1}{|c|}{ Sectores } & \multicolumn{2}{|c|}{ 3.1- Têxteis } & \multicolumn{2}{c|}{ 3.2- Confecções } \\
\hline \multicolumn{1}{|c|}{ Indicadores } & $\begin{array}{c}\text { Rácio 1980 } \\
\text { menos a Rácio } \\
1988\end{array}$ & $\begin{array}{c}\text { Rácio média de } \\
\text { crescim. têxtil } \\
\text { menos Rácio } \\
\text { crescim. Indúst. } \\
(1980-1988)\end{array}$ & $\begin{array}{c}\text { Rácio 1980 } \\
\text { menos a Rácio } \\
1988\end{array}$ & $\begin{array}{c}\text { Rácio média de } \\
\text { crescim. confec- } \\
\text { ção menos Rácio } \\
\text { crescim. Indúst. } \\
\text { (1980-1988) }\end{array}$ \\
\hline Produção & $(1)$ & $(1)$ & $-8.03 \%$ & $+3.67 \%$ \\
Valor Acrescentado & $+14.71 \%$ & $-1.49 \%$ & $-10.27 \%$ & $+4.14 \%$ \\
Investmento Equip. & $-14.94 \%$ & $+2.83 \%$ & $-7.89 \%$ & $+4.77 \%$ \\
Emprego & $-10.40 \%$ & $+0.82 \%$ & -25.39 & $+4.49 \%$ \\
Exportação & $+24.23 \%$ & $-2.37 \%$ & $-57.01 \%$ & $+7.76 \%$ \\
\hline
\end{tabular}

\begin{tabular}{|l|c|c|}
\hline \multicolumn{1}{|c|}{ Sectores } & \multicolumn{2}{|c|}{ 3.3- Confecç̃es - Têxteis } \\
\hline Indicadores & Confeç̧̃os-Têxteis (1) & $\begin{array}{c}\text { Diferença entre Rácios de } \\
\text { crescim. Confeçб̃es - Diferença } \\
\text { entre Rácios de crescim. dos Têxteis }\end{array}$ \\
\hline Produção & $-22.74 \%$ & $+5.16 \%$ \\
Valor Acrescentado & $-28.06 \%$ & $+5.54 \%$ \\
Investimento Equip. & $+7.06 \%$ & $+1.93 \%$ \\
Emprego & $-14.99 \%$ & $+3.87 \%$ \\
Exportação & $-81.24 \%$ & $+10.13 \%$ \\
\hline
\end{tabular}

Fonte: INE

(1) $\frac{\text { Indicador para o sector em } 198 \ldots}{\text { Indicador para o total da indústria em } 198 \ldots} * 1000$

Da análise deste quadro, o comportamento -padrão do Têxtil foi bastante diferente do das Confecções. O sector Têxtil viu reduzida a sua importância em termos de produção, valor acrescentado e exportações; as rácios de crescimento no 
sector têxtil de fiação destas mesmas variáveis foram inferiores às do resto da indústria. Em contraste com este sector, as Confecções aumentaram o seu peso, relativamente ao resto da indústria, em dois pontos percentuais (tendo como base o Produto Nacional). Podemos considerar que estes dois subsectores tiveram duas performances distintas: as confecções com comportamento positivo e os têxteis com um comportamento negativo. Estas conclusões podem ser comprovadas quando confrontamos os dados referentes aos dois subsectores (tabela 3.3).

No entanto, verificamos que desde 1988 , e nos anos sucessivos até 1992, o subsector das confecções teve sensivelmente as mesmas tendências que o têxtil, no que respeita aos indicadores Valor Acrescentado e Emprego, embora não tão acentuadas. Esta inversão é devida essencialmente aos seguintes factores:

- Aumento do custo da mão-de-obra não compensado pelo aumento da produtividade; o que levou à perda de competitividade do sector nos segmentos de mercado tradicionais (segmento médio e médio/baixo, em que o factor preço é bastante importante).

- Diferencial de inflação nacional com os principais parceiros comerciais (UE) bastante elevado; o que levou o sector a não poder efectuar os ajustamentos anuais dos preços com base na inflação interna.

- Alteração da política cambial seguida nos anos oitenta (desvalorização deslizante do escudo), com a entrada da moeda nacional para o mecanismo das taxas de câmbio do Sistema Monetário Europeu (SME).

- Inexistência na maioria das empresas de uma gestão moderna, apoiada nas técnicas de Marketing que as salvaguardasse do impacto negativo da alteração das variáveis macroeconómicas.

Analisando o parágrafo anterior podemos dizer que a situação, durante a década de noventa, tenderá a degradar-se ainda mais, a não ser que exista uma profunda reestruturação do sector.

\section{AS CAUSAS DA CRISE}

Existem duas formas de explicar não só os maus momentos que este sector atravessa, como as diferentes «performances» dos dois subsectores. As explicações podem ser dadas em termos de valor acrescentado, ou antes, atendendo aos factores que não foram devidamente explorados pelo sector para aumentar o seu valor acrescentado, e ainda em termos de proximidade relativamente ao consumidor final (ou seja, em termos de mercado final). 


\subsection{Em termos de valor acrescentado}

A matriz seguinte fornece-nos algumas pistas relativamente às causas da crise explicada em termos de valor acrescentado. Ao construirmos uma matriz de segmentação do mercado e se, em cada um desses segmentos, identificarmos os operadores dos mesmos em termos de funções de Marketing ou de Produção temos:

\section{MATRIZ DE SEGMENTAÇÃO DO MERCADO DAS CONFECÇÕES}

\begin{tabular}{|c|c|c|c|c|}
\hline $\begin{array}{l}\text { Segmentos } \\
\text { Funções }\end{array}$ & $\begin{array}{c}\text { Baixa } \\
\text { relação } \\
\text { Qualidade/Preço }\end{array}$ & $\begin{array}{c}\text { Média-Baixa } \\
\text { relação } \\
\text { Qualidade/Preço }\end{array}$ & $\begin{array}{c}\text { Média } \\
\text { relação } \\
\text { Qualidade/Preço }\end{array}$ & $\begin{array}{c}\text { Média-Alta } \\
\text { e Alta relação } \\
\text { Qualidade/Preço }\end{array}$ \\
\hline Marketing & 1 & 2 & 3 & 4 \\
\hline $\begin{array}{l}\text { - Canais de Dis- } \\
\text { tribuição }\end{array}$ & $\begin{array}{l}\text { - Grandes ca- } \\
\text { deias de re- } \\
\text { talhistas (gran- } \\
\text { des espaços) }\end{array}$ & $\begin{array}{l}\text { - Cadeias de re- } \\
\text { talhistas (peque- } \\
\text { nos espaços) }\end{array}$ & $\begin{array}{l}\text { - Pequenas ca- } \\
\text { deias de reta- } \\
\text { lhistas }\end{array}$ & - Marcas \\
\hline - Marcas & & $\begin{array}{l}\text { - Venda directa } \\
\text { por correspon- } \\
\text { dência }\end{array}$ & $\begin{array}{l}\text { - Pequenos catá- } \\
\text { logos }\end{array}$ & - Boutiques \\
\hline $\begin{array}{l}\text { - Inovação (no- } \\
\text { vos model./de- } \\
\text { sign) }\end{array}$ & & $\begin{array}{l}\text { - Grandes catá- } \\
\text { logos }\end{array}$ & $\begin{array}{l}\text { - Companhias } \\
\text { comerciais }\end{array}$ & \\
\hline \multirow[t]{2}{*}{ Produção } & $\begin{array}{l}5 \\
\text { - Países Asiáti- } \\
\text { cos }\end{array}$ & $\begin{array}{l}6 \\
\text { - Países Asiáti- } \\
\text { cos }\end{array}$ & 7 & $\begin{array}{l}8 \\
\text { - Itália }\end{array}$ \\
\hline & - Norte de África & $\begin{array}{l}\text { - Indonésia } \\
\text { - Países do Leste } \\
\text { Europeu }\end{array}$ & - PORTUGAL & $\begin{array}{l}\text { - Alemanha } \\
\text { - França }\end{array}$ \\
\hline
\end{tabular}

O sector das Confecções em Portugal opera no segmento caracterizado pela célula n. ${ }^{\circ} 7$, ou seja, é um sector essencialmente produtor, cujos clientes na sua grande maioria são companhias comerciais, pequenos catálogos e cadeias de reta- 
lhistas de pequena dimensão, em que os produtos possuem uma média relação preço/qualidade. Além do mais, isto significa que a indústria portuguesa de confeç̧ões não controla os canais de distribuição de escoamento dos seus produtos e, por sua vez, não possui marcas internacionalmente conhecidas; em suma, não funciona numa lógica de Marketing.

Podemos identificar dois aspectos que o sector não tem conseguido dominar e que lhe daria um maior valor acrescentado:

- Controlar os canais de distribuição no segmento onde estão a operar, inovar com a criação de design próprio e criar marcas próprias com imagem.

- O segundo aspecto que daria às empresas portuguesas um maior valor acrescentado, dentro do mesmo segmento em que operam, é trazido por um aumento da qualidade dos seus produtos. Para o conseguir, as empresas têm de mudar de uma situação em que a sua produção se baseia num pequeno número de grandes encomendas, para uma situação em que o número de encomendas é grande mas de pequeno tamanho.

No primeiro aspecto considerado, o factor crítico de sucesso é o Preço (custo); no segundo aspecto os factores críticos de sucesso são a Qualidade (cor, moda e aspectos técnicos dos produtos) e o cumprimento dos prazos de entrega.

Além das dificuldades em fazerem aumentar estes dois aspectos, as empresas portuguesas enfrentam hoje uma situação que é influenciada por um terceiro factor: estas não podem aumentar os preços dos seus produtos no mercado internacional, devido à concorrência vinda dos países que operam no segmento representado pela célula 6 (países Asiáticos e do Leste Europeu) e mesmo dos países da célula 8 (Itália, Alemanha e França.).

Se, por um lado, a concorrência ao nível do preço tem sido grande para as empresas portuguesas, os seus custos, comparados com os das empresas estrangeiras não têm cessado de aumentar, devido a: elevadas taxas de juro, inflação e à valorização do escudo nos mercados cambiais.

\subsection{Em termos de mercado final.}

As empresas portuguesas, ao venderem os seus produtos principalmente a agentes comerciais, não dominam nem conhecem o seu consumidor final, quer ao nível das suas características intrínsecas (atitudes, poder de compra, padrões de comportamento e necessidades satisfeitas), quer ao nível das suas motivações de compra. Com a moda passa-se um facto extremamente importante, que é o de as 
empresas portuguesas se tornarem menos competitivas devido à sua incapacidade de produzir o que o mercado solicita; as capacidades de inovação (novos modelos e design) e de criar marcas (imagem) são muito incipientes. Moda é um conceito diferente de Qualidade dos Produtos (confecção perfeita, qualidade das matérias-primas, resistência e durabilidade).

Se construirmos um quadro em que relacionemos a importância do factor Moda, nos vários tipos de produtos, relativamente à sua distância do consumidor final, podemos determinar exactamente qual a posição das empresas portuguesas em relação aos seus consumidores.

\section{Tipos de Produtos}

\begin{tabular}{|c|c|c|}
\hline & $\begin{array}{c}\text { Produtos em que a moda é } \\
\text { muito importante }\end{array}$ & $\begin{array}{c}\text { Produtos em que a moda não } \\
\text { é importante }\end{array}$ \\
\hline Distante do consumidor final & $\begin{array}{l}\text { 1- Ausência de Marketing } \\
\text { (inovação e marcas). } \\
\text { 2- Forte concorrência dos } \\
\text { países europeus e do } \\
\text { terceiro mundo. } \\
\text { 3- Não detêm o controlo } \\
\text { dos canais de distri- } \\
\text { buição. }\end{array}$ & $\begin{array}{l}\text { 1- Forte concorrência dos } \\
\text { países europeus e do ter- } \\
\text { ceiro mundo. } \\
\text { 2- Não detêm o controlo } \\
\text { dos canais de } \\
\text { distribuição. }\end{array}$ \\
\hline Próximo do consumidor final & $\begin{array}{l}\text { 1- Ausência de Marketing } \\
\text { (inovação e marcas) } \\
2 \text { - Não detêm o controlo dos } \\
\text { canais de distribuição. }\end{array}$ & $\begin{array}{l}1 \text { - Não detêm o controlo dos } \\
\text { canais de distribuição. }\end{array}$ \\
\hline
\end{tabular}

As empresas portuguesas encontram-se na posição caracterizada pela célula assinalada, o que significa que as empresas nacionais têm qualidade mas não colocam moda nos seus produtos.

\section{O FUTURO DA INDÚSTRIA DE CONFECÇÕES}

Os quadros seguintes pretendem mostrar qual o segmento de mercado onde operam as empresas portuguesas de confecção, quais os aspectos mais importantes para o seu sucesso em cada um dos diferentes subsegmentos (Factores Críti- 
cos de Sucesso) e quais as vantagens comparativas relativamente aos seus concorrentes.

Ao tentarmos dividir o segmento onde operam as empresas portuguesas (célula 7), tendo como referenciais a distância das empresas relativamente ao seu consumidor final, por um lado e, por outro, a importância do factor moda dos seus produtos, verificamos que podemos dvidir a célula $7 \mathrm{em}$ quatro subsegmentos (A, B, C e D).

\section{Célula 7}

\begin{tabular}{|c|c|}
\hline $\begin{array}{c}\text { Produtos onde } \\
\text { o factor moda } \\
\text { não é importante }\end{array}$ & $\begin{array}{c}\text { Produtos onde } \\
\text { o factor moda } \\
\text { é muito importante }\end{array}$ \\
\hline
\end{tabular}
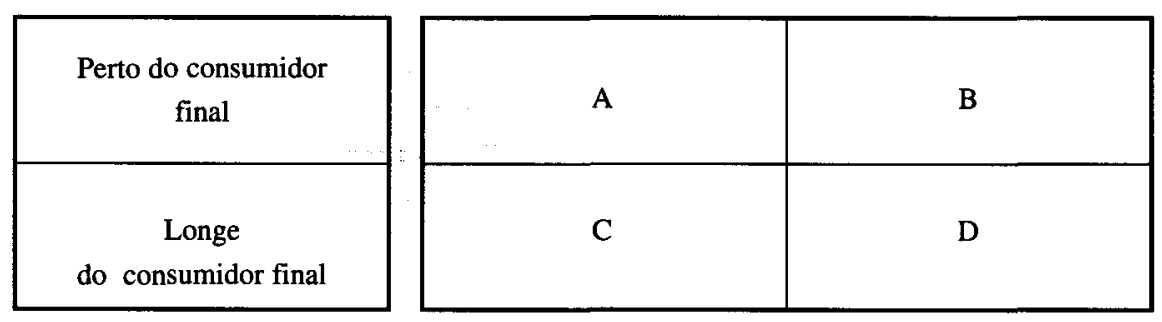

Em cada um destes subsegmentos os factores críticos de sucesso (FCS) são os representados no quadro seguinte.

\begin{tabular}{|c|c|c|}
\hline & $\begin{array}{c}\begin{array}{c}\text { Produtos onde } \\
\text { o factor moda } \\
\text { não é importante }\end{array} \\
\text { FCS=Prazos de entrega }\end{array}$ & $\begin{array}{c}\begin{array}{c}\text { Produtos onde } \\
\text { o factor moda } \\
\text { é muito importante }\end{array} \\
\text { FCS=Adapta/Flexibilidade }\end{array}$ \\
\hline $\begin{array}{l}\text { Perto do consumidor final } \\
\text { FCS=Qualidade }\end{array}$ & $\begin{array}{l}\text { A } \\
\text { FCS=Qualidade } \\
\text { FCS=Prazos de entrega }\end{array}$ & $\begin{array}{l}\text { B } \\
\text { FCS=Qualidade } \\
\text { FCS=Prazos de entrega }\end{array}$ \\
\hline $\begin{array}{l}\text { Longe do consumidor final } \\
\text { FCS=Preço }\end{array}$ & $\begin{array}{l}\text { C } \\
\text { FCS=Preço } \\
\text { FCS=Prazos de entrega }\end{array}$ & $\begin{array}{l}\text { D } \\
\text { FCS=Preço } \\
\text { FCS=Adapta.Flexibilidade }\end{array}$ \\
\hline
\end{tabular}


Para facilitar a análise deste quadro, devemos fazer os seguintes comentários:

a) Os produtos de moda intensiva requerem muita inovação (design), na função Marketing, e Adaptabilidade/Flexibilidade, na função Produção. Estes são os factores críticos de sucesso dos produtos de moda da célula 7 .

b) Adaptabilidade/Flexibilidade diz respeito às entregas das encomendas correctamente (em termos de design e confecção), no tempo certo e na quantidade correcta. Isto depende da dimensão das empresas, seu equipamento, sua organização e proximidade geográfica do mercado consumidor.

c) Nos produtos onde a moda não é importante, o design daqueles e a sua confecção muda menos frequentemente. Somente o cumprimento dos prazos de entrega é um factor crítico de sucesso.

d) Por razões de simplicidade, em cada célula são indicadas somente as variáveis mais críticas. Isto não quer dizer que as restantes sejam de desprezar.

e) Também para simplificar esta análise, os dois Factores Críticos de Sucesso indicados em cada célula assumem a mesma importância.

Como se infere desta análise, o futuro da indústria de confecções no nosso país depende das vantagens e/ou desvantagens competitivas relativas a cada um dos factores críticos de sucesso em cada célula, comparadas com os seus mais directos concorrentes.

No quadro seguinte apresentamos a posição das empresas portuguesas nos vários subsegmentos da célula 7 , tendo em conta os vários FCS. 


\begin{tabular}{|c|c|c|c|}
\hline $\begin{array}{c}\quad \begin{array}{c}\text { O sector em } \\
\text { Portugal }\end{array} \\
\text { comparado com } \rightarrow \\
\text { em termos de }\end{array}$ & $\begin{array}{l}\text { Os países Europeus } \\
\text { mais desenvolvidos } \\
\text { (PEMD) } \\
\text { (1) }\end{array}$ & $\begin{array}{l}\text { Países do terceiro } \\
\text { mundo } \\
\text { (PTM) } \\
\text { (2) }\end{array}$ & $\begin{array}{l}\text { Qual dos países } \\
\text { concorrentes é } \\
\text { melhor que } \\
\text { Portugal em termos } \\
\text { de cada um dos } \\
\text { FCS. }\end{array}$ \\
\hline \multicolumn{4}{|l|}{ Subsegmento A } \\
\hline Qualidade & igual & vantagem & nenhum \\
\hline Prazos de entrega & desvantagem & vantagem & PEMD (1) \\
\hline \multicolumn{4}{|l|}{ Subsegmento B } \\
\hline Quaiidade & desvantagem & vantagem & PEMD \\
\hline Adapt./Flexibilidade & desvantagem & vantagem & PEMD \\
\hline \multicolumn{4}{|l|}{ Subsegmento C } \\
\hline Prazos de entrega & desvantagem & vantagem & PEMD \\
\hline Preço & igual & desvantagem & PTM (2) \\
\hline \multicolumn{4}{|l|}{ Subsegmento D } \\
\hline Adapt./Flexibilidade & desvantagem & vantagem & PEMD \\
\hline Preço & igual & desvantagem & PTM \\
\hline
\end{tabular}

(1) Países Europeus Mais Desenvolvidos.

(2) Países do Terceiro Mundo (incluindo os países do Leste Europeu).

Quando avaliamos vantagens e desvantagens temos que ter em conta o tipo específico de segmento de mercado, grupo de produtos e sua tecnologia.

Da análise do quadro anterior, verificamos que o subsegmento onde as empresas portuguesas possuem uma posição mais competitiva é o A, e aqueles onde a posição competitiva é substancialmente mais fraca são o C e o D. Assim, podemos considerar que as empresas portuguesas de confecções se encontram encur168 raladas entre dois tipos de concorrente: em termos de preço, países do terceiro 
mundo e, em termos de qualidade e prazos de entrega, países europeus mais desenvolvidos.

Tendo em consideração os movimentos estratégicos dos países concorrentes, podemos construir uma matriz onde se identificam essas ameaças. Assim temos:

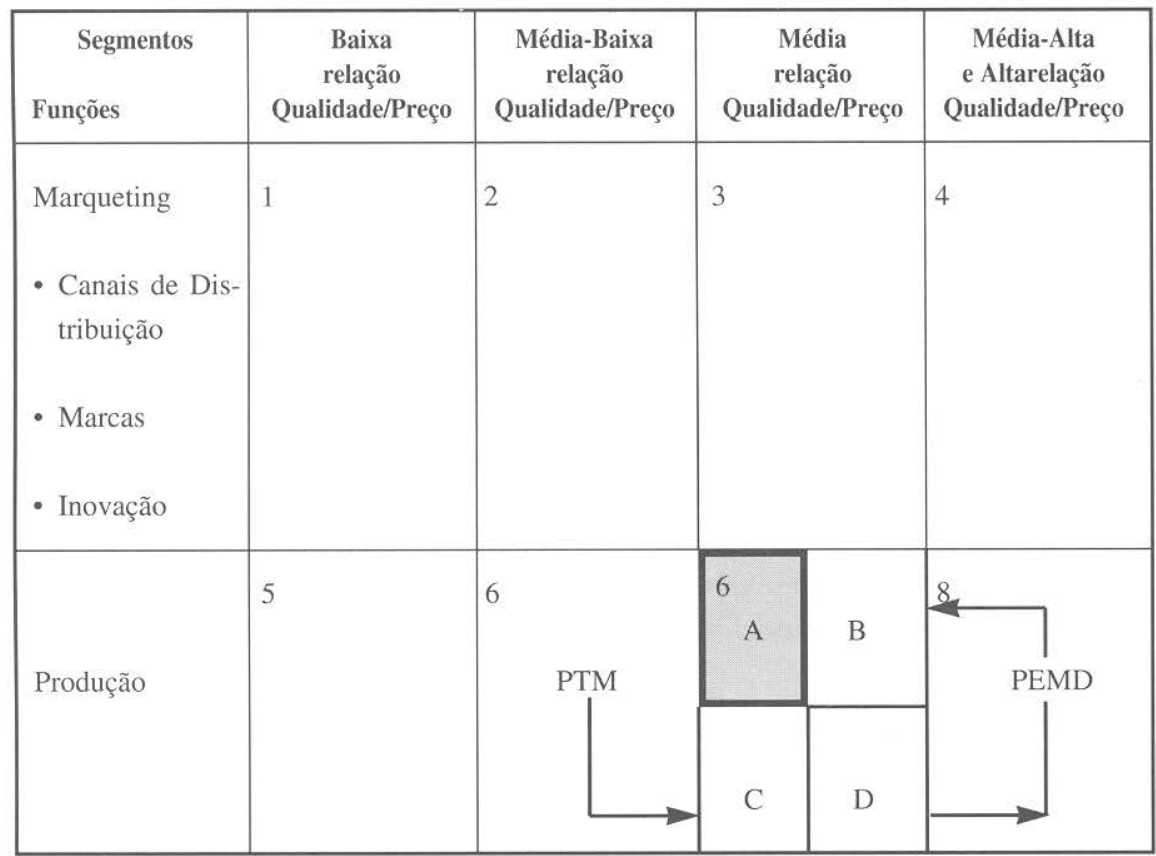

As ameaças às PME's nacionais no sector das confecções, mantendo-se estas a operar no segmento de mercado actual (Média relação Qualidade/Preço) e numa função meramente produtiva, surgem simultaneamente de duas direç̧ões. Por um lado, à medida que os PVD incrementam a sua eficiência face ao cumprimento dos prazos de entrega, estes penetram no subsegmento $\mathrm{C}$, pressionando as empresas portuguesas; por outro, os PEMD já ocupam o subsegmento B, sendo mais competitivos neste mercado. Verificando-se um maior crescimento do custo dos factores de produção (mão-de-obra, energia, fraca produtividade do sector administrativo do Estado e elevados custos financeiros, etc.), no nosso país, relativamente aos PEMD, naturalmente estes irão ocupar o subsegmento $\mathrm{D}$, pois passam a ter preços próximos dos nacionais (exemplo actual é a vizinha Espanha que, neste momento, já possui preços de confecção iguais aos nacionais).

Assim, o único subsegmento de mercado onde as PME's nacionais, de facto, possuem alguma vantagem competitiva é o representado pela letra A. 
Segundo as análises estratégicas efectuadas ao sector das confecções em Portugal (nomeadamente a efectuada por Vasconcelos e Sá, no início da década de noventa, em que nos baseámos nos pontos 3 e 4 deste artigo) (cfr. bibliografia), apontava-se para que as nossas empresas se deslocassem estrategicamente da célula 7 , onde se encontravam (e ainda se encontram), para a célula 3. Isto quer dizer que estas se deveriam manter no mesmo segmento de mercado, mas passar a incorporar funções comerciais e de marketing no seu funcionamento, controlando para isso os canais de distribuição, introduzindo desing nos seus produtos e implementando políticas de imagem (marcas).

O que hoje questionamos, com alguma relevância, é se deverá ser esse o movimento mais correcto da nossa indústria de confecções e qual o grau de transformação adequado ao mercado dos finais dos anos noventa, tendo em atenção as rápidas transformações socioeconómicas. Do ponto de vista da modificação estrutural das nossas empresas de confecção, estas não possuem um único movimento estratégico possível e adequado, como referido anteriormente, mas sim três caminhos distintos para que obtenham graus de competitividade elevados, face a todos os países concorrentes e que garantem no futuro a sobrevivência saudável das empresas nacionais.

Assim, na matriz de segmentação seguinte são identificados os três movimentos estratégicos mencionados:

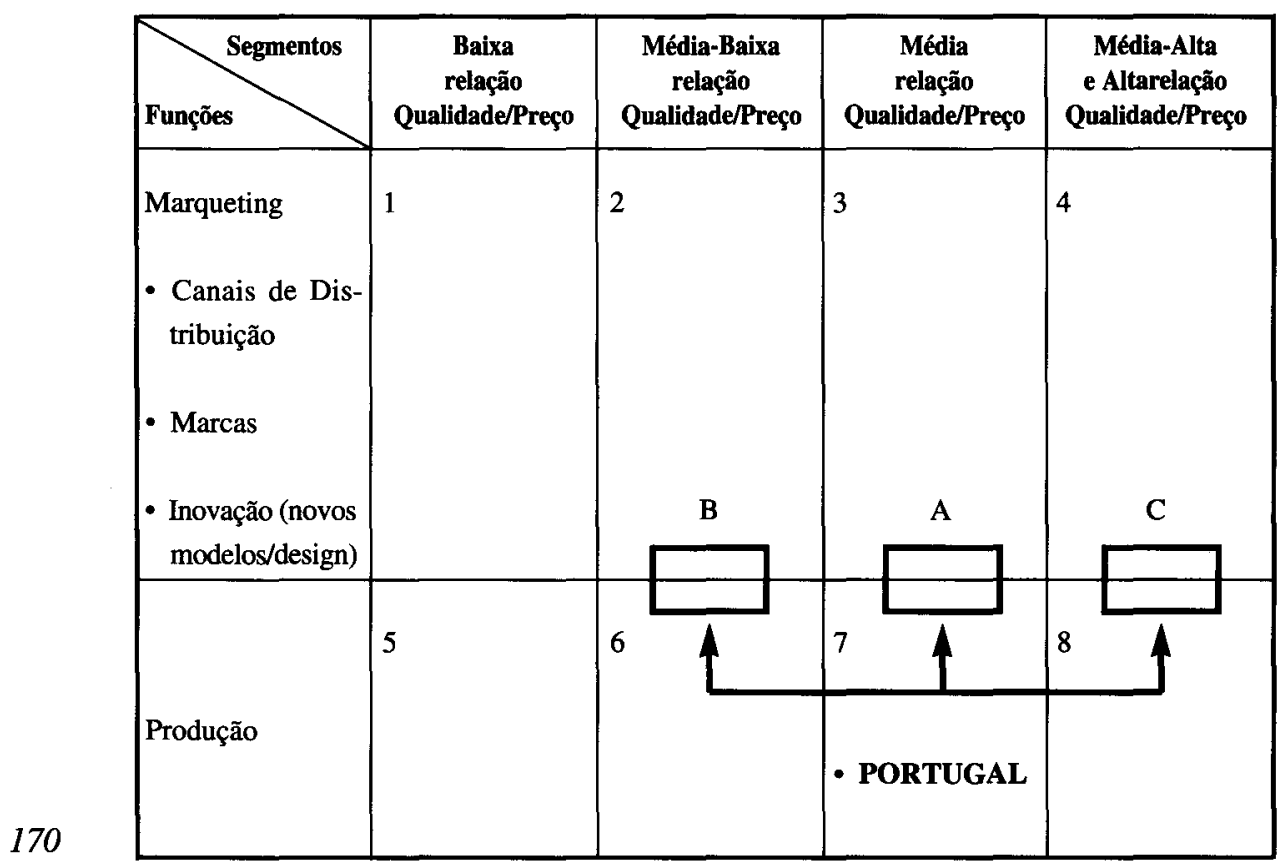




\section{ESTRATÉGIA A - Célula $7 \rightarrow$ Célula 3}

Corresponde à deslocação das empresas dentro do mesmo segmento de mercado (Média relação Qual./Preço), mas abandonando grande parte da sua função produção e passando a funcionar numa lógica de marketing, controlando os canais de distribuição, criando marcas e introduzindo design próprio nos seus produtos.

\section{ESTRATÉGIA B - Célula $7 \rightarrow$ Célula 2}

Corresponde à deslocação das empresas para outro segmento de mercado, o médio-baixo e passa a incorporar simultaneamente as funções comerciais e de marketing .

\section{ESTRATÉGIA C - Célula $7 \rightarrow$ Célula 4}

Corresponde a uma deslocação das empresas para outro segmento de mercado, médio alto-alto e adoptando simultaneamente uma postura comercial e de marketing.

Assim, analisemos as vantagens e desvantagens destas três soluções possíveis, face ao estado actual das empresas nacionais do sector e face ao nível de gestão que estas actualmente possuem. 


\begin{tabular}{|c|c|c|c|}
\hline & ESTRATÉGIA A & ESTRATÉGIA B & ESTRATÉGIA C \\
\hline $\begin{array}{l}\text { Taxa de crescimento } \\
\text { do segmento de } \\
\text { mercado. }\end{array}$ & $\begin{array}{l}\text { O segmento médio } \\
\text { tem taxas de } \\
\text { crescimento } \\
\text { negativas. }\end{array}$ & $\begin{array}{c}\text { O segmento médio- } \\
\text {-baixo tem taxas de } \\
\text { crescimento atrac- } \\
\text { tivas }(8 \% \text { ano). }\end{array}$ & $\begin{array}{l}\text { O segmento médio } \\
\text { alto-alto tem taxa de } \\
\text { crescimento nula. } \\
\text { Este mercado atingiu } \\
\text { a maturidade. }\end{array}$ \\
\hline Preço. & $\begin{array}{l}\text { A nivel mundial o } \\
\text { preço médio dimi- } \\
\text { nui cerca de } 16 \% \text { ao } \\
\text { ano em cada peça. }\end{array}$ & $\begin{array}{l}\text { O preço é estável e } \\
\text { não se prevê gran- } \\
\text { des variações a } \\
\text { médio prazo. }\end{array}$ & $\begin{array}{l}\text { Preço estável com } \\
\text { alguma tendência a } \\
\text { descer no médio } \\
\text { prazo. }\end{array}$ \\
\hline Distribuição. & $\begin{array}{l}\text { - Pequenas cadeias } \\
\text { de retalho a perde- } \\
\text { rem o poder de } \\
\text { compra. } \\
\text { - Companhias comer- } \\
\text { ciais a serem pressi- } \\
\text { onadas pelas novas } \\
\text { formas de distribui- } \\
\text { ção (Zara, Beneton, } \\
\text { etc.). } \\
\\
\text { - Pequenos catálogos } \\
\text { ainda com algum } \\
\text { poder de compra, } \\
\text { mas no médio prazo } \\
\text { serão absorvidos } \\
\text { pelos catálogos dos } \\
\text { Department Stores. }\end{array}$ & $\begin{array}{l}\text { Prevê-se o aumento } \\
\text { do poder de com- } \\
\text { pra por parte dos } \\
\text { grandes catálogos. } \\
\text { - Entrada dos Depar- } \\
\text { tment Stores e } \\
\text { grandes cadeias de } \\
\text { retalho neste seg- } \\
\text { mento de mercado, } \\
\text { com uma nova } \\
\text { filosofia de parte- } \\
\text { nariado com os } \\
\text { seus fornecedores. }\end{array}$ & $\begin{array}{l}\text { Distribuição trans- } \\
\text { formada em lojas } \\
\text { monomarca, em al- } \\
\text { guns casos utili- } \\
\text { zando o franchizing. }\end{array}$ \\
\hline Gestão & $\begin{array}{l}\text { Implementação de no- } \\
\text { vas formas de pla- } \\
\text { neamento e orga- } \\
\text { nização, bem como } \\
\text { a utilização de uma } \\
\text { filosofia de marke- } \\
\text { ting. }\end{array}$ & $\begin{array}{l}\text { Implementação de no- } \\
\text { vas formas de pla- } \\
\text { neamento e orga- } \\
\text { nização, bem como } \\
\text { a utilização de } \\
\text { uma filosofia de } \\
\text { marketing. }\end{array}$ & $\begin{array}{l}\text { Implementação de no- } \\
\text { vas formas de pla- } \\
\text { neamento e organi- } \\
\text { zação, bem como a } \\
\text { utilização de uma } \\
\text { filosofia de marke- } \\
\text { ting. }\end{array}$ \\
\hline Produto & $\begin{array}{l}\text { Não são necessárias } \\
\text { grandes transforma- } \\
\text { ções. }\end{array}$ & $\begin{array}{l}\text { O produto fabricado } \\
\text { actualmente é de } \\
\text { qualidade intrín- } \\
\text { seca superior ao } \\
\text { necessário. }\end{array}$ & $\begin{array}{l}\text { É necessário melhorar } \\
\text { substancialmente a } \\
\text { qualidade dos pro- } \\
\text { dutos a fabricar. }\end{array}$ \\
\hline Serviço pós-venda & $\begin{array}{l}\text { Aumentar a qualidade } \\
\text { do serviço. }\end{array}$ & $\begin{array}{l}\text { Aumentar a quali- } \\
\text { dade do serviço. }\end{array}$ & $\begin{array}{l}\text { Aumentar a qualidade } \\
\text { do serviço. }\end{array}$ \\
\hline $\begin{array}{l}\text { Esforço de investi- } \\
\text { mento }\end{array}$ & $\begin{array}{l}\text { Principalmente em } \\
\text { marketing e design. }\end{array}$ & $\begin{array}{l}\text { Principalmente em } \\
\text { marketing. }\end{array}$ & $\begin{array}{l}\text { Principalmente em } \\
\text { marketing, quali- } \\
\text { dade e formação. }\end{array}$ \\
\hline
\end{tabular}

Fonte: - Estudo de mercado Europeu, realizado pela ESP Research \& Marketing.

- Rui Quinaz e A. Morais, Plano de Marketing, 1994, Branaldo,.

172 - CTCOE, Centre Textile de Conjoncture et D'Observation Economique/Clichy. Estudos de mercado para 1994 


\section{CONCLUSÃO}

Face ao nível de gestão das empresas nacionais, à sua estrutura organizativa, financeira e de recursos humanos, pensamos que a solução mais consistente no médio e longo prazo é a ESTRATÉGIA B. Para isso, julgamos positivo que as PME's nacionais deste sector conservem parte da sua capacidade produtiva e passem a sustentar o seu funcionamento em aspectos comerciais e de marketing, e que, simultaneamente, passem a operar no segmento médio-baixo ou alto do mercado. A movimentação, no que diz respeito ao segmento de mercado a escolher, deve ser feita tendo em atenção a competitividade de cada uma das empresas relativamente aos factores críticos de sucesso em cada segmento.

\section{BIBLIOGRAFIA}

BOURNEUF, Prespectives de Consommation et d'Activite du Secteur Textile-Habillementen en 1994, (C.T.C.O.E., Novembro.

CENTRE TEXTILE DE CONJONCTURE ET D'OBSERVATION ECONOMIQUE, «Zoom sur les Marches de l'Habillement et des Textiles de Maison», Novembro 1993.

DEVEZ, «Les Comportementes des Consommateurs Face au Prix» (C.T.C.O.E. - Seminaires du 4 Novembre 1993).

ESPRESEARCH \& MARKETING, «European Market Research Stouy of Denim.

INE Análise de Conjuntura da Década de 80.

MUSGRAVE, 1993, «Price Sensitivy», Sportswear International, n. ${ }^{\circ}$ 10, Editorial.

QUINAZ \& MORAIS, «Plano de Marketing 1994 — Branaldo», Agosto 1993.

SÁ, Vasconcelos, 1991, Portuguese Textiles: The Future Arrived Earlier.

SOLVING - INTERNATIONAL, «La Nouvelle Donne du Textile - Habillement Europeen», Dezembro de 1993. 